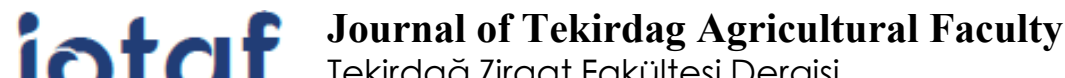 \\ Tekirdağ Ziraat Fakültesi Dergisi
}

\section{Antep Fıstığı Kabuğu ve Zeytin Küspesinden Biyoyakıt Amaçlı Pelet Elde Edilmesi}

Pellet Production From Pistachio Shell And Olive Cake For Biofuels

\author{
Hatice Cansu DEVELI' ${ }^{1}$, Ali AYBEK ${ }^{2}$, Serdar ÜÇOK ${ }^{3 *}$
}

\section{$\ddot{\mathbf{O z}}$}

Ülkemizde önemli bir potansiyele sahip olan bitki atıklarının biyoyakıt amaçlı enerji kaynağı olarak kullanılması önem kazanmaktadır. Bu atıklardan enerji elde etmek için birçok yöntem bulunmakta olup bu yöntemlerden bir tanesi de peletlemedir. Bu çalışmada Antep fistığı işleme ve kavlatma tesisinden alınan Antep fistı̆̆ kabuğu (AK), zeytinyağı işleme tesisinden alınan zeytin küspesinden (ZK) biyoyakıt amaçlı pelet elde edilmesi ve elde edilen peletlerin fiziksel, kimyasal ve mekanik özelliklerinin belirlenmesi amaçlanmıştır. Denemelerde materyallerin 5 farklı oranda (\%100 AK, \%75 AK+\%25 ZK, \%50 AK+\%50 ZK, \% 25AK+\%75 ZK ve \%100 ZK) karıștırılması ile peletler elde edilmiştir. Peletleme işlemi $6 \mathrm{~kW}$ motor gücüne sahip ve işleme kapasitesi $70-90 \mathrm{~kg} \mathrm{~h}^{-1}$ olan dairesel sıralı delikli düz kalıplı peletleme makinesinde yapılmıştır. Çalışmada pelet parça yoğunluğu 973.70$1191.96 \mathrm{~m}^{3} \mathrm{~kg}^{-1}$, kırılma direnci \%99.21-99.87 ve nem alma oranı \%19.12-22.24 arasında bulunmuştur. Maksimum pelet parça yoğunluğu \%100 ZK karışımında, dikey basma gerilme direnci \%100 AK'da meydana gelmiştir. Peletlerin nem içeriği Avrupa Pelet Konseyince belirlenen standartlara uygun bulunmuştur. En düşük uçucu madde miktarına sahip materyal \%100 AK'de iken, en yüksek uçucu madde miktarına sahip materyal \%25 AK+\%75 ZK karışımında görülmüştür. Maksimum dikey sıkıştırma direnci \%100 AK'da gerçekleşmiştir. Peletlerin kül içeriği değerleri \%5.97 ile \%10.08 arasında bulunmuştur. Kırılmaya karşı en hassas materyal \%50 $\mathrm{AK}+\% 50 \mathrm{ZK}$ karışımında gerçekleşirken kırılmaya karşı en dayanıklı materyal \%100 AK'da tespit edilmiştir. Pelet çap ve uzunlukları EN16127 standardına uygun olduğu görülmüş̧ür. Dikey sıkıştırma dirençleri ise 157.17$235.08 \mathrm{~N}$ arasında değişmiştir. Değerler birbirine yakın olmakla birlikte en fazla nem alma \%100 ZK'de gözlenmiştir. Ülkemizde potansiyel ve çeşitliliği fazla olan yeterince değerlendirilemeyen biyoyakıt kaynakları; pelet haline getirilerek ülke ekonomisine katkı sağlayabilir.

Anahtar Kelimeler: Antep fistığı kabuğu, Zeytin küspesi, Biyoyakıt, Pelet, Enerji

\footnotetext{
*3Sorumlu Yazar/Corresponding Author: Serdar ÜÇOK, Kahramanmaraş Sütçü İmam Üniversitesi, Ziraat Fakültesi, Biyosistem Mühendisliği Bölümü, Kahramanmaraş, Türkiye. E-mail: sucok@ksu.edu.tr (D) OrcID: 0000-0002-7158-669X

${ }^{1}$ Hatice Cansu DEVELİ, Kahramanmaraş Sütçü İmam Üniversitesi, Ziraat Fakültesi, Biyosistem Mühendisliği Bölümü, Kahramanmaraş, Türkiye. E-mail: hcansudeveli@gmail.com (D) OrcID: 0000-0002-5094-956X

${ }^{2}$ Ali Aybek, Kahramanmaraş Sütçü İmam Üniversitesi, Ziraat Fakültesi, Biyosistem Mühendisliği Bölümü, Kahramanmaraş, Türkiye. E-mail: aaybek@ksu.edu.tr (D) OrcID: 0000-0003-3036-8204

Atıf/Citation: DEVELI, H.C., AYBEK, A., ÜÇOK, S. Antep Fıstığı Kabuğu ve Zeytin Küspesinden Biyoyakıt Amaçlı Pelet Elde Edilmesi. Tekirdağ Ziraat Fakültesi Dergisi, 18 (4), 689-701.

(CBu çalışma Tekirdağ Namık Kemal Üniversitesi tarafından Creative Commons Lisansı (https://creativecommons.org/licenses/by-nc/4.0/) kapsamında yayınlanmıştır. Tekirdağ 2021 


\begin{abstract}
Plant wastes, which have a significant potential in our country, are used as biofuel energy sources and gain importance. There are various methods for obtaining energy from these wastes. One of these methods is pelleting method. The aim of study is pellet production from pistachio shell (PS) that obtained from the pistachio processing plant and spent olive cake (OC) which obtained from olive oil processing plant together with identification of physical, chemical and mechanical properties of the produced pellets. 5 different pellets were produced by 5 different combinations of pistachio shells and olive cakes $(100 \%$ PS, $75 \%$ PS $+25 \%$ OC, $50 \%$ PS $+50 \%$ OC, $25 \%$ PS $+75 \%$ OC ve $100 \%$ OC). Pelletization was done with the circular, tiered perforated and plain formed pelletizing machine which has $6 \mathrm{~kW}$ engine power and $70-90 \mathrm{~kg} \mathrm{~h}^{-1}$ slicing capacity. In the study, pellet density, fracture strenght and dehumidification ratio were found between $973.70-1191.96 \mathrm{~m}^{3} \mathrm{~kg}^{-1}, 99.21-99.87 \%$ and $19.12-22.24 \%$, respectively. Maximum pellet density was found in \%100 OC mix, vertical compressive stress resistance was found in $100 \%$ PS mix. Moisture content values of pellets are appropriate for the Europe Pellet Council standards. While the lowest volatile substance content has been measured in $100 \%$ PS, the highest volatile substance content was measured in $25 \%$ PS $+75 \%$ OC mix. Maximum vertical compressive stress resistance occured in $100 \%$ PS. Ash content of the pellets were between $5.974 \%$ and $10.083 \%$. While the most sensitive material to be broken is $50 \% \mathrm{PS}+50 \% \mathrm{OC}$, the most enduring material to be broken is $100 \%$ PS. Pellet diameter and lenghts are appropriate for EN16127 standards. Vertical compressive stress resistance are between 157.17 and $235.08 \mathrm{~N}$. The most dehumidification rate was seen in $100 \%$ OC, while values are so close. Our country has good potential and diversity for biofuel sources but can not be used efficiently. These sources must be used as pellet forms and be made a big contribution to country economy.
\end{abstract}

Keywords: Pistachio shell, Olive cake, Biofuel, Pellet, Energy 


\section{Giriş}

Toplumların kalkınma ve gelişme düzeylerini arttırmak amacıyla gerçekleştirdikleri ilerlemeler enerji tüketim hızında artışlara sebep olmaktadır. Dünya genelinde kullanılmakta olan enerji kaynaklarının birçoğunu fosil enerji kaynakları oluşturmaktadır (Aybek ve ark., 2015). Enerji kaynakları kullanımına göre, alternatif (yenilenebilir) ve fosil (yenilenemez) enerji kaynakları olmak üzere ikiye ayrılmaktadır. Ancak fosil kaynak rezervlerinin mevcut enerji ihtiyacını ilerleyen yıllarda karşılayamayacağı ve rezervlerin tükeneceği öngörülmektedir (Şenpınar ve Gençoğlu, 2006). Fosil enerji kaynaklarının en önemli dezavantajı yakıldıkları zaman iklim değişikliğine neden olan kirletici özelliğe sahip sera gazlarını yaymaları ve küresel ısınmaya yol açarak asit yağmurlarının oluşmasına neden olmasıdır. Fosil kaynak rezervlerinin sınırlı olması yenilenebilir enerji kaynaklarının ilerleyen yıllarda öneminin artacağını göstermektedir (Dağtekin ve Gürdil, 2021).

Yenilenebilir enerji, enerji temininde sürekliliğe sahip ve doğal süreçler sonucunda oluşmaktadır. Bu enerji kaynaklarının enerji üretiminde daha çok rol alması ile karbondioksit emisyonlarını azaltarak çevrenin korunması sağlanabilir ve enerjide dışa bağımlılık minimum düzeye indirilebilir (Çapık, 2012). Yenilenebilir enerji kaynaklarından olan biyoyakıt enerjisi doğa dostu, ekonomik, güvenli ve enerji üretmede işletme maliyetleri az olarak bilinmektedir (Özdemir ve Er, 2018). Hammaddesi tarımsal ve hayvansal kökenli atıkların çeşitli biyokimyasal ve termokimyasal işlemler uygulanarak elde edilen katı, sıvı ve gaz ürünlere biyoyakıt denilmektedir. Ayrıca endüstriyel, kentsel ve evsel atıklardan da biyoyakıt elde etmek mümkündür. Katı biyoyakıtlar iki başlıkta incelenmektedir (Karaosmanoğlu, 2006). Geleneksel olan katı biyoyakıtlar günlük hayatta sıklıkla uygulanmakta olup odunlar, ağaç dalları vb. olan yakıtların işlem görmeden yakılmasıdır. Modern katı biyoyakıt ise materyalin işlenmesi sonucunda yeni bir yakıt oluşturulması işlemi olup yakıtın daha verimli kullanılmasını sağlamaktadır. Modern biyoyakıt için hammaddelere ögütme işlemi uygulanarak daha küçük parçalar elde edilip sonrasında yüksek basıncın etkisiyle sıkıştırılarak daha büyük kütleye sahip yakıtlar oluşturulmaktadır. Elde edilen yakıtlar ısınma ihtiyacında, elektrik enerjisinin temininde de kullanılabilmektedir. En önemli uygulanma şekli peletler ve briketlerden meydana gelmektedir (Karaosmanoğlu, 2006).

Enerjiye olan gereksinimin sürekli artış gösterdiği günümüz şartlarında fosil kaynaklar yerine yeni ve yenilenebilir kaynak arayışı devam etmektedir. Yenilenebilir enerji kaynakları içerisinde yer alan biyokütle önemli bir yer tutmaktadır (Diken ve Kayişoğlu, 2020). Materyallerin biyoyakıt amaçlı peletleme işlemi sonucunda hacimsel 1sı değerinde artış sağlanırken taşıma ve depolama maliyetlerinde azalma görülür. Ayrıca yanma özelliklerinde iyileşme gözlemlenir. Atmosfere salınan parçacıkların emisyonunda azalma görülür. Aynı boyut veya şekle sahip daha üstün özellikler elde edilir. Gelişmiş ülkelerin birçoğunda katı olan atıklar, biyokütleye peletleme işlemi uygulanarak yararlı, kullanılabilir ve ekonomik ürünler elde edilebilmektedir. Ülkemizde enerji amaçlı pelet üzerine yapılan çalışmalar peletlemenin yaygınlaşmasını sağlayıp veri tabanını güçlendirecektir. (Aydemir, 2017).

Tarım ve tarıma dayalı sanayide oluşan ürün atıklarının enerji kaynağı olarak katı yakıt formuna sahip olarak aktif bir şekilde değerlendirilmesi önem taşımaktadır. Bu amaçla, söz konusu atıklar kurutulup, öğütüldükten sonra preslenerek biyoyakıt amaçlı pelet haline getirilebilir. Biyokütle kaynaklı olan Antep fistığı kabuğu ve zeytin küspesi atıklarının organik madde miktarları yüksek olması nedeniyle peletleme açısından önemli atıklardır.

$\mathrm{Bu}$ çalışmanın genel amacı; Antep fistığı kabuğu ve zeytin küspesi atıklarından biyoyakıt amaçlı pelet elde eve elde edilen peletlerin fiziksel ve kimyasal, fiziko-mekanik ve termal özelliklerini belirlemektir.

\section{Materyal ve Metot}

\subsection{Materyal}

Araştırma Kahramanmaraş Sütçü İmam Üniversitesi Ziraat Fakültesi Biyosistem Mühendisliği Bölümü Laboratuvarlarında yürütülmüsşür. Araştırmada materyal olarak Antep fistı̆̆ı işleme ve kavlatma tesisinden alınan Antep fıstığı kabuğu (Şekil 1) ve zeytinyağı işleme tesisinden alınan zeytin küspesi (Şekil 2) kullanılmıştır. Pelet üretiminde elde edilen materyaller ilk olarak doğal şekilde güneşte kurutulduktan sonra ögütülmüştür. 


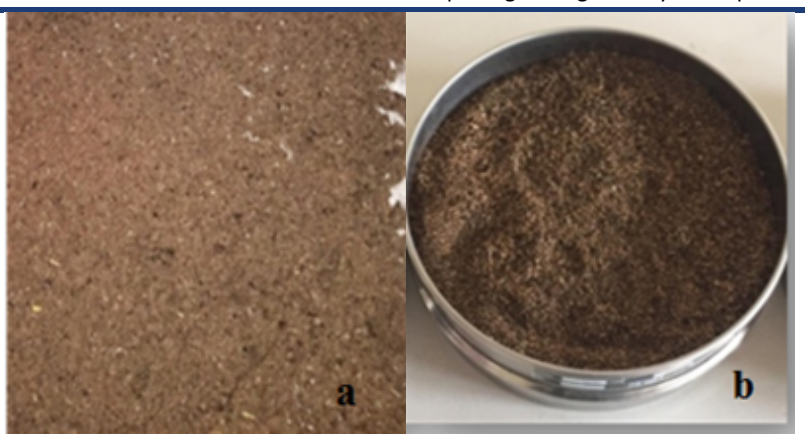

Figure 1. Wet pistachio shell (a) and pistachio shell after drying-grinding process (b)

Şekil 1. Yaş Antep fistı̆̆ı kabuğu atıkları (a) ve kurutma-ö̆̆̈̈tme işlemi tamamlanmış Antep fistı̆̆ı kabuğu attkları (b)

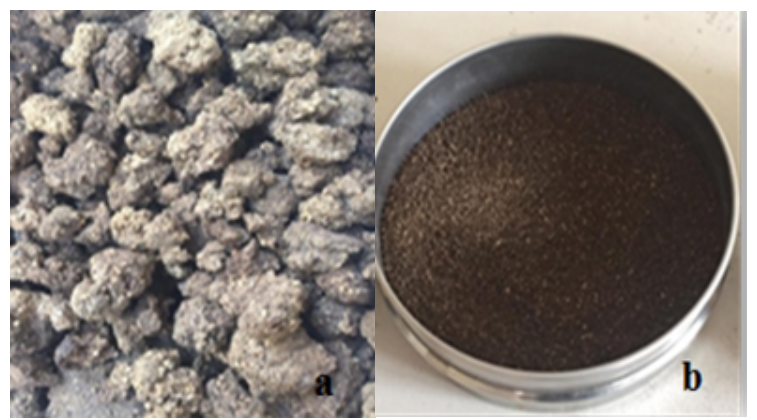

Figure 2. Wet olive pulp (a) and olive pulp after drying-grinding process (b)

Şekil 2. Yaş zeytin küspesi (a) ve kurutma-öğütme işlemi tamamlanmış zeytin küspesi (b)

Peletleme işlemi için laboratuar tipi, motor gücü $6 \mathrm{~kW}$ olan ve $70-90 \mathrm{~kg} \mathrm{~h}^{-1}$ işleme kapasitesine sahip dairesel sıralı delikli düz kalıplı redüktör dönü sayısı $96 \mathrm{~d} \mathrm{dak}^{-1}$ peletleme makinesi kullanılmıştır (Şekil 3).

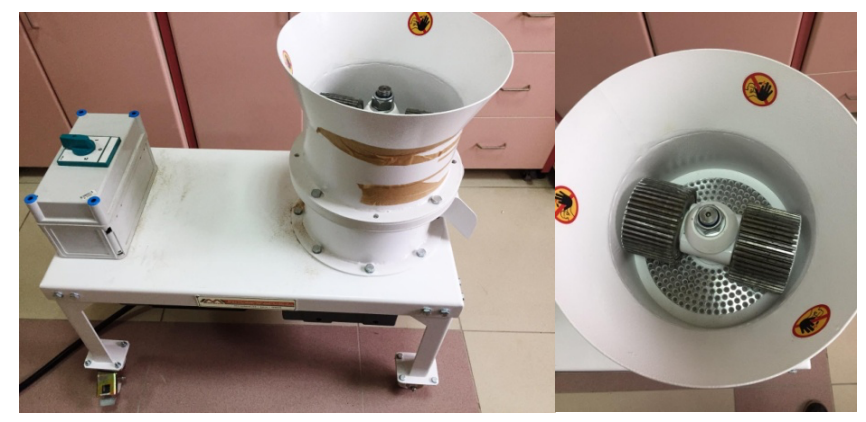

Figure 3. Pelletizing machine

Şekil 1. Peletleme makinesi

\subsection{Metot}

Antep fistığı kabuğu (AK) ve zeytin küspesi (ZK) atıkları ilk olarak doğal şekilde güneş altında kurutulup öğütüldükten sonra materyallerin kuru kütle bazında karışım oranları (\%) ve karışımların isimlendirilmeleri Tablo l'de verilmiştir.

Tablo 1. Pelet yapımında kullanılan materyallerin kuru kütle bazında karışım oranları (\%) Table 1. Mix ratio (\%) of materials used in pellet production on dry mass basis

\begin{tabular}{cccccc}
\hline Materyal & Karışım-1 & Karışım-2 & Karışım-3 & Karışım-4 & Karışım-5 \\
\hline AK $(\%)$ & 100 & 0 & 50 & 75 & 25 \\
ZK $(\%)$ & 0 & 100 & 50 & 25 & 75 \\
\hline
\end{tabular}


Peletleme işlemi öncesinde her karışım ayrı ayrı bir kaba alınıp her birine peletlerin bağlayıcılığı artması amacıyla $\% 5$ oranında sıvı melas eklenerek homojen karışımlar elde edilmiştir. Karışımlar peletleme işlemi için bir kap yardımıyla pelet makinesine boşaltılmıştır. Elde edilen peletlerden (Şekil 4) sonra her karışım için pelet makinesi temizlenip işlem tekrarlanmıştır.

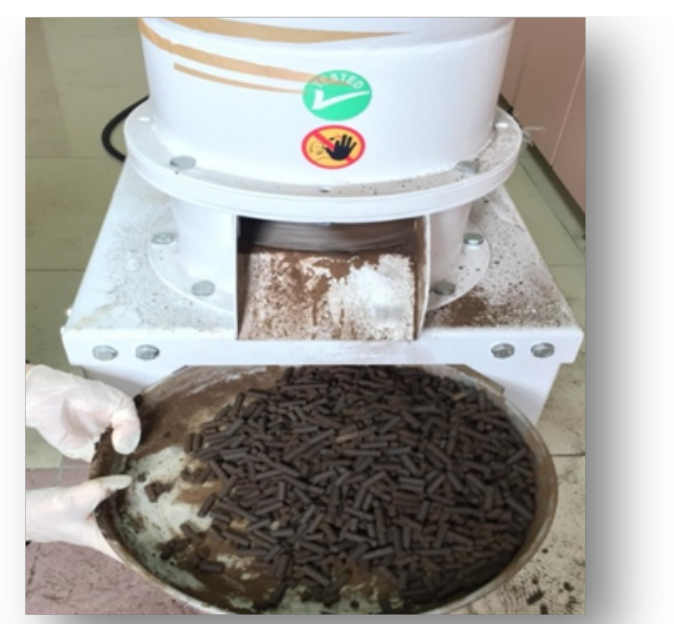

Figure 4. View of the pellets obtained

Şekil 4. Elde edilen peletlerin görünümü

Peletlerin; kül içeriği analizi, TS ISO 1171 standardı esas alınarak, nem içeriği ASTMD 3173 standardına göre, uçucu madde içeriği analizi, TS ISO 562 standardına göre, sabit karbon içeriği analizi, ASTMD 3172 standardına göre, toplam karbon ve azot içeriği analizleri AOAC (1990) yöntemine göre belirlenmiştir. Pelet parça yoğunluğunun belirlenmesi amacıyla her pelet örneğinden 40 adet pelet rastgele seçilmiştir. Daha sonra şeçilen peletler ( 0.001 hassasiyetli) hassas terazide tartılarak kütleleri kaydedilmiştir. Tartım sonrasında silindir şeklindeki peletlerin çapı ve uzunluğu $0.01 \mathrm{~mm}$ hassasiyete sahip dijital kumpas yardımı ile ölçülerek peletlerin özgül hacmi $\left(\mathrm{kg} \mathrm{m}^{-3}\right)$ hesaplanmıştır. Toplam karbon $(\mathrm{C})$ ve azot $(\mathrm{N})$ analizleri elemental analiz cihazı (Leco marka Truspec Micro) ile yapılmıştır.

Peletlerin kırılma dirençlerinin belirlenmesi amacıyla rastgele seçilmiş 4 adet pelet $1.80 \mathrm{~m}$ yükseklikten sert bir zemine $4 \mathrm{kez}$ serbest bırakılmıştır. Peletler $3.15 \mathrm{~mm}$ delik çapındaki elekte elenmiştir. Eleme işlemi sonunda kütleleri tartılıp ilk kütlelerine oranlanmıştır. Hesaplamada Eşitlik 1 kullanılmıştır (Yılmaz, 2014).

$\mathrm{K}_{\mathrm{d}}=\frac{\mathrm{m}_{\mathrm{e}}}{\mathrm{m}_{\mathrm{a}}} \times 100$

Eşitlikte;

$K_{d}:$ Kirllma direnci (\%)

$m_{e}$ : Test öncesi pelet kütlesi (g)

$m_{a}$ : Test sonrası pelet kütlesi (g)'dir.

Peletlerin üst ısıl değeri Eşitlik 2 yardımıyla hesaplanmışıtır (Baileys ve Blankenhorn, 1982).

$\mathrm{HHV}=0.312 \mathrm{FC}+0.1534 \mathrm{VC}$

Eşitlikte;

HHV: Üst 1sıl değer $(\mathrm{MJ} / \mathrm{kg})$

FC: Sabit karbon (\%)

VC: Uçucu madde içeriği (\%)'dir.

Peletlerin sıkıştırma direnci Newton (N) olarak Eşitlik 3 yardımıyla hesaplanmıştır (Liu ve ark., 2014). 
$\sigma_{x}=\frac{2 F}{\pi d l}$

Eşitlikte;

$\sigma_{x}$ : Dikey basma gerilme direnci $(\mathrm{N})$

$F$ : Maksimum kırılma kuvveti $(\mathrm{N})$

$d$ : Pelet çapı (m)

1: Pelet uzunluğu (m)'dur.

Pelet nem alma oranları pelet kütlesindeki değişim yöntemi ile belirlenmiştir. Pelet nem alma oranının belirlenmesinde beş farklı karışım içerisinden rastgele seçilen 5 adet pelet, etüvde $105 \pm 2{ }^{\circ} \mathrm{C}$ sıcaklıkta sabit kütle değerine ulaşıncaya kadar yaklaşık olarak 24 saat bekletilmiştir. Kurutma sonrasında peletlerin ilk kütlesi kaydedilmiş ve $\% 90$ nem içeriğinde $27{ }^{\circ} \mathrm{C}$ sıcaklığa sahip iklimlendirme kabininde 24 saat bekletilerek tekrar tartılmıştır (Eşitlik 4). Peletlerin nem alma oranları yüzde (\%) olarak hesaplanmıştır. (Atay, 2015; Başıüyü̈k, 2020).

$\mathrm{Pa}=\frac{(\mathrm{mf}-\mathrm{mi})}{\mathrm{mi}} * 100$

Eşitlikte;

Pa: Nem alma oranı (\%)

mi: Pelet materyallerin ilk kütlesi (g)

mf: Pelet materyallerin son kütlesi (g)'dir.

Peletlerin yanma özelliklerinin belirlenebilmesi için termogravimetrik analizler yapılmıştır. Her karışımdan alınan 20-25 mg numuneler seramik krozelere konularak 30-920 ${ }^{\circ} \mathrm{C}^{\prime}$ ye kadar $10{ }^{\circ} \mathrm{C}$ dak ${ }^{-1}$ ' lik tarama hızında, 20 $\mathrm{mL}$ dak$^{-1}$ ' lık akış hızında analizler yapılmıştır. Bu sıcaklık aralığında meydana gelen kütle kaybı ve kütle kayıp oranı TGA analizörü (PerkinElmer TG/DTA model) ile grafiğe yansıtılmıştır. Yapılan analiz sonrasında termogravimetrik analizler (TGA) ve diferansiyel termogravimetrik analiz (DTG) verileri elde edilmiştir.

Araştırmada, tüm veriler 3 tekerrürlü olarak ölçülmüş ve ortalama değerler alınıp istatistiksel analizi (SPSS, One Way Anova, Tukey) yapılmıştır. Bulunan değerler şekil ve tablolara aktarılarak yorumlanmıştır.

\section{Araştırma Sonuçları ve Tartışma}

\subsection{Peletlerin fiziksel ve Kimyasal Özellikleri}

Araştırmada peletlerin elemental analizi $(\mathrm{C}, \mathrm{N}, \mathrm{H}(\%))$ ve üst 1 sıl değerleri, pelet parça yoğunluğu, dikey sıkıştırma direnci, nem içeriği, nem alma direnci, kırılma direnci, uçucu madde, sabit karbon ve kül içeriği analizleri belirlenmiştir.

Peletlerin elemental analizi sonunda; C, N, H (\%) değerleri ve ayrıca üst 1sıl değerleri belirlenmiştir (Tablo 2). Peletlerin; N değerleri \%4.31-4.62, C değerleri \%48.1-52.1, H değerleri \%7.38-8.06 ve üst ısıl değerleri ise 16.17$18.38 \mathrm{MJ} \mathrm{kg}^{-1}$ arasında belirlenmiştir. Maksimum azot miktarı \%4.62 ile \%50 AK+\%50 ZK' de, maksimum karbon miktarı \%52.1 ile \%100 AK'de, maksimum hidrojen miktarı ise \%8.06 ile \%100 AK'de ve maksimum üst 1s1l değeri \%75 AK+ \%25 ZK' de ölçülürken minimum N ve H (\%) değerleri \%100 ZK' de, minimum C (\%) değeri \%50 $\mathrm{AK}+\% 50 \mathrm{ZK}$ 'de ve minumum üst 1 sıl değeri \%100 ZK' de belirlenmiştir.

Pelet ile yapılan çalışmalarda; Tırıs (2014), biyokütle enerji içerikleri ve biyokütle karakterizasyonu üzerine yaptığ 1 araştırmada elemental analiz sonucunda $\mathrm{C}(\%)$ değeri \%42.98-\%58.83, H (\%) değeri \%4.08-\%6.8, N (\%) değeri ise \%0.12-\%4.72 aralığında bulmuştur. Bu çalışmada elde edilen değerler Tırıs (2014) çalışması ile kıyaslandığında; N ve H (\%) değerlerinin uyumlu olduğu fakat H (\%) değerleri Tırıs (2014) yaptığı çalışmadaki değerlerden yüksek olduğu belirlenmiştir. Bu durumun, materyal ve kimyasal içerik farklılığından kaynaklandığ söylenebilir. Karışımdaki AK miktarı arttıkça H (\%) miktarının da arttığı gözlemlenmiştir. Peletlerin üst 1 sıl değerlerine bakıldığında elde edilen değerlerin birbirine yakın olduğu görülmektedir. Ancak N (\%) değerlerinde \%100 ZK için \%4.31, \%100 AK için \%4.43 olduğu görülmektedir. İki materyalin karıştırılmasıyla 
elde edilen karışım değerlerinin \%4.31-\%4.43 aralığında olmamasının sebebi sistematik örneklem hatasından kaynaklandığı söylenebilir.

Tablo 2. Peletlerin elemental analizi ve üst ısıl değerleri

Table 2. Elemental analysis and Higher heating value of pellets

\begin{tabular}{|c|c|c|c|c|c|}
\hline \multirow[b]{2}{*}{$\begin{array}{l}\text { Peletlerin elemental analiz } \\
\text { ve üst Isıl değerleri }\end{array}$} & \multicolumn{5}{|c|}{ Pelet karışımları } \\
\hline & $\frac{8}{8}$ & 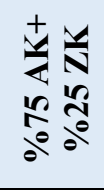 & 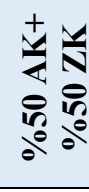 & 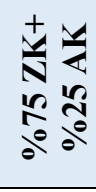 & $\begin{array}{l}\frac{y}{N} \\
\frac{\Xi}{0} \\
\frac{0}{0}\end{array}$ \\
\hline $\mathrm{N}(\%)$ & 4.43 & 4.46 & 4.62 & 4.59 & 4.31 \\
\hline $\mathrm{C}(\%)$ & 52.1 & 49.2 & 48.1 & 48.8 & 48.6 \\
\hline $\mathrm{H}(\%)$ & 8.06 & 7.64 & 7.42 & 7.51 & 7.38 \\
\hline Üst 1sıl değeri $\left(\mathrm{MJ} \mathrm{kg}^{-1}\right)$ & 17.96 & 18.38 & 16.17 & 17.67 & 17.14 \\
\hline
\end{tabular}

Peletlerin ortalama çap, uzunluk, kütle ve pelet parça yoğunluk değerleri Tablo 3'de verilmiştir. Pelet çapları 6.45-6.78 mm, pelet uzunluklarının 21.85-34.71 mm, pelet kütleleri 0.78-1.39 g ve pelet parça yoğunlukları 973.70-1191.96 kg m³ arasında belirlenmiştir. Avrupa Pelet Konseyi tarafından hazırlanan el kitabında belirtilen EN16127 standardına göre pelet çapları 6-8 mm, pelet uzunlukları ise 3.15-40 mm arasında standart değer kabul edilmektedir. Çalışmada elde edilen verilere göre pelet çap ve uzunlukları EN16127 standardına uygun olduğu tespit edilmiştir. Araştırmada ZK oranı artıkça pelet parça yoğunluğunun arttığı görülmüştür. Karışımlar arası pelet parça yoğunluklarında önemli düzeyde farklılık bulunmuştur $(\mathrm{P}<0.05)$. Atay ve ark. (2018) şeftali çekirdeği ve linyit kömür tozu ile yaptığı peletlerin parça yoğunluğunu 905.30-1000.40 $\mathrm{kg} \mathrm{m}^{-3}$ olarak belirlemişlerdir. Bu çalışmada elde edilen değerler Atay ve ark. (2018) tarafından bulunan değerlerle kıyaslandığında, \%100 AK haricinde parça yoğunlukların daha yüksek olduğu görülmüştür. Bu farklılığın nedeninin atıkların fiziksel özelliklerinin farklı olmasından kaynaklandığı dünülmektedir.

Tablo 3. Peletlerin çap, uzunluk, kütle ve parça yoğunluğu

Table 3. Diameter, length, weight and particle density of pellets

\begin{tabular}{ccccc}
\hline Peletler & $\begin{array}{c}\text { Çap } \\
(\mathbf{m m})\end{array}$ & $\begin{array}{c}\text { Uzunluk } \\
(\mathbf{m m})\end{array}$ & $\begin{array}{c}\text { Kütle } \\
(\mathbf{g})\end{array}$ & $\begin{array}{c}\text { Pelet parça } \\
\text { yoğunluğu } \\
\left(\mathbf{k g ~ m}^{-3}\right)\end{array}$ \\
\hline$\% 100 \mathrm{AK}$ & 6.48 & 24.29 & 0.78 & $973.70 \mathrm{e}$ \\
\hline$\% 100 \mathrm{ZK}$ & 6.78 & 32.30 & 1.39 & $1191.96 \mathrm{a}$ \\
\hline$\% 75 \mathrm{AK}+\% 25 \mathrm{ZK}$ & 6.41 & 33.57 & 1.14 & $1003.84 \mathrm{~d}$ \\
\hline$\% 25 \mathrm{AK}+\% 75 \mathrm{ZK}$ & 6.45 & 31.25 & 1.07 & $1047.91 \mathrm{~b}$ \\
\hline$\% 50 \mathrm{AK}+\% 50 \mathrm{ZK}$ & 6.57 & 34.71 & 1.13 & $1018.07 \mathrm{c}$ \\
\hline
\end{tabular}

Satır içerisinde aynı harfleri alan değerler arasında istatiksel olarak anlamlı bir fark yoktur $(P<0.05)$.

Peletlerin kırılma direnci \%99.21-\%99.87 aralığında bulunmuştur. Çalışmada en yüksek kırılma direnci \%99.87 ile \%100 AK'de meydana gelirken, kırılmaya karşı en hassas materyal \%50 AK+\%50 ZK'de oluşmuştur (Tablo 4). Karışımlar arası kırılma direncinde önemli düzeyde farklılık bulunmamıştır $(\mathrm{P}<0.05)$. Aydemir (2017) kenevir sapları, findık ve çeltik atıklarını materyal olarak kullanarak pelet kırılma direncini \%99.33-\%99.90, Yılmaz (2014) ise pamuk sapları ve susam saplarını materyal olarak kullandığı çalışmada pelet kırılma direnci \%99.26-\%99.71 değerleri arasında belirlemiştir. Bu çalışmada elde edilen kırılma direnci değerleri, Aydemir (2017) ve Yılmaz (2014)'ün bildirmiş olduğu değerlerle uyumlu olduğu görülmüştür.

Dikey sıkıştırma dirençleri 157.17-235.08 N arasında bulunmuştur (Tablo 4). Dikey sıkıştırma değeri; maksimum $235.08 \mathrm{~N}$ ile \%100 AK'de olurken minimum ise \%100 ZK'de 157.17 N olarak belirlenmiştir. AK oranı arttıkça dikey sıkıştırma direncinin arttığı görülmüştür. Karışımlar arası dikey sıkıştırma dirençlerinde önemli düzeyde farklılık bulunmuştur $(\mathrm{P}<0.05)$. Atıklarının peletlenmesi ile oluşan peletlere uygulanan dikey sıkıştırma direnci çalışmalarında; Bilgin ve ark. (2016) çay fabrikası atıklarında en yüksek basınç değerini 476 N, GarsiaMaraver ve ark. (2010) zeytin dalı ve yapraklarında en yüksek basınç değerini $220 \mathrm{~N}$ olarak belirlemişlerdir. Bu 

çalışmada yapılan dikey sıkıştırma direnci denemesi sonucunda elde edilen değerler, Bilgin ve ark. (2016) tarafından bulunan değerlerden düşük olduğu ancak Garsia-Maraver ve ark. (2010) tarafından bulunan değerlere yakın olduğu görülmektedir. Bu farklılıkların olmasının nedeni materyal farklılığından kaynaklandığı söylenebilir.

Peletlerin nem içeriği \%5.40-\%6.70 arasında bulunmuştur (Tablo 4). Bu değerler, EN14774-1 standardında belirtilen değerlerden $(\leq \% 10)$ küçük olup standartlara uygundur. Karışımlar arası nem içeriklerinde önemli düzeyde farklılık bulunmuştur $(\mathrm{P}<0.05)$. Atay ve Ekinci, (2020) linyit kömür tozu ve kızılçam ağaç kabuğunun nem içeriği değerlerini \%5.39-\%9.15 arasında olduğunu belirtmiştir. Pelet nem içeriği değerleri, bu çalışma ile kıyaslandığında her ikisinin de EN14774-1 standardında belirtilen değer aralığında olduğu görülmüştür.

Peletlerin taşıma veya depolanması sırasında, hava koşulları veya yüksek nispi nem koşulları pelet kalitesini etkilemektedir (Kaliyan ve Morey 2009). Peletlerin depolanmasında nem alması peletlerin dayanımlarını azaltmaktadır (Tabil, 1996; Fasina ve ark. 1996). Peletlerin nem alma değerleri Tablo 4'de verilmiştir. Değerler birbirine yakın olmakla birlikte en fazla nem alma \%22.69 ile \%100 ZK'de, en az nem alma ise \%19.12 ile \%100 AK'da gözlenmiştir. Çalışmada ZK oranı artıkça nem alma oranı artmıştır. Karışımlar arası nem alma dirençlerinde önemli düzeyde farklılık bulunmamıştır $(\mathrm{P}>0.05)$.

Peletlerin uçucu madde miktarları, sabit karbon ve kül içeriği değerleri Tablo 5'de verilmiştir. En düşük uçucu madde miktarına sahip materyal \%100 AK'de \%52.87 iken, en yüksek uçucu madde miktarına sahip materyal \% 100 ZK' de \%64.83 olarak belirlenmiştir. ZK oranı artıkça uçucu madde miktarında artma görülmüştür. Karışımlar arası uçucu madde miktarlarında önemli düzeyde farklılık bulunmamıştır $(\mathrm{P}<0.05)$. Uçucu madde miktarları ile yapılan çalışmada; Atay ve Ekinci (2020) tarafından yağ gülü damıtma atıkları, linyit kömür tozu ve kızılçam ağaç kabuğundan linyit kömür tozunun \%75 oranda kullanıldığı karışımda \%43.8 iken kızılçam ağaç kabuğunun \%75 oranda olduğu karışımda ise \%68.5 olarak hesaplamıştır. Bu veriler yapılan araştırma ile benzerlik göstermektedir.

Tablo 4. Peletlerin kırılma direnci, dikey sıkıştırma direnci, nem içeriği, nem alma değerleri

Table 4. Fracture resistance, vertical compression strength, moisture content, moisture uptake values of pellets

\begin{tabular}{lcccc}
\hline Peletler & $\begin{array}{c}\text { Kirılma direnci } \\
(\%)\end{array}$ & $\begin{array}{c}\text { Dikey sıkıştırma } \\
\text { direnci }(\mathbf{N})\end{array}$ & $\begin{array}{c}\text { Nem içeriği } \\
(\%)\end{array}$ & $\begin{array}{c}\text { Nem alma direnci } \\
(\%)\end{array}$ \\
\hline$\% 100 \mathrm{AK}$ & $99.87 \mathrm{a}$ & $235.08 \mathrm{a}$ & $5.40 \mathrm{bc}$ & $19.12 \mathrm{a}$ \\
$\% 100 \mathrm{ZK}$ & $99.78 \mathrm{a}$ & $157.17 \mathrm{e}$ & $5.46 \mathrm{bc}$ & $22.69 \mathrm{a}$ \\
$\% 75 \mathrm{AK}+\% 25 \mathrm{ZK}$ & $99.62 \mathrm{a}$ & $210.76 \mathrm{~b}$ & $5.26 \mathrm{c}$ & $20.26 \mathrm{a}$ \\
$\% 25 \mathrm{AK}+\% 75 \mathrm{ZK}$ & $99.51 \mathrm{a}$ & $167.19 \mathrm{~d}$ & $6.12 \mathrm{ab}$ & $22.24 \mathrm{a}$ \\
$\% 50 \mathrm{AK}+\% 50 \mathrm{ZK}$ & $99.21 \mathrm{a}$ & $181.29 \mathrm{c}$ & $6.70 \mathrm{a}$ & $21.49 \mathrm{a}$ \\
\hline
\end{tabular}

Satır içerisinde aynı harfleri alan değerler arasında istatiksel olarak anlamlı bir fark yoktur $(P<0.05)$.

Peletlerin uçucu madde miktarları, sabit karbon ve kül içeriği değerleri Tablo 5' de verilmiştir. En düşük uçucu madde miktarına sahip materyal \%100 AK'de \%52.87 iken, en yüksek uçucu madde miktarına sahip materyal \% 100 ZK' de \%64.83 olarak belirlenmiştir. ZK oranı artıkça uçucu madde miktarında artma görülmüştür. Karışımlar arası uçucu madde miktarlarında önemli düzeyde farklılık bulunmamıştır $(\mathrm{P}<0.05)$. Atay ve Ekinci $(2020)$ tarafından yağ gülü damıtma atıkları, linyit kömür tozu ve kızılçam ağaç kabuğundan linyit kömür tozunun \%75 oranda kullanıldığı karışımda \%43.8 iken kızılçam ağaç kabuğunun \%75 oranda olduğu karışımda ise \%68.5 olarak hesaplamıştır. Bu veriler yapılan araştırma ile benzerlik göstermektedir.

Sabit karbonun yanması sonucu ortaya çıkan inorganik atık olarak tanımlanan kül, yanma teknolojisinin belirlenmesinde önemli bir parametredir (Garcia ve ark., 2014). Peletlerin sabit karbon değerleri \%21.26-\%31.63 arasında belirlenmiştir (Tablo 5). Karışımlar arası sabit karbon değerlerinde önemli düzeyde farklılık bulunmuştur $(\mathrm{P}<0.05)$. Bu değerler, Atay ve Ekinci (2020) tarafından yağ gülü damıtma atıkları, linyit kömür tozu ve kızılçam ağaç kabuğu ile yapmış olduğu araştırmada sabit karbon değerlerini \%13.09-\%32.49 arasında olduğunu bildirmiştir. Sabit karbon değerleri yapılan bu çalışma ile benzer aralıkta bulunmuştur.

Peletlerin kül içeriği değerleri \%5.97-\%10.08 arasında bulunmuştur (Tablo 5). Maksimum kül içeriğine sahip materyal \%100 ZK'de görülmüştür. Karışımdaki zeytin küspesi miktarı arttıkça kül içeriği değeri doğrusal olarak artmıştır. Karışımlar arası kül içeriği değerlerinde önemli düzeyde farklılık bulunmuştur $(\mathrm{P}<0.05)$. Avrupa Pelet Konseyi EN plus-A1, En plus-A2 ve EN-B sınıfı olmak üzere üç standart belirlemiştir. EN plus-A1 için kül içeriği 
değeri \%0.7'den düşük, En plus-A2 için kül içeriği değeri \%1.5'den düşük ve EN-B sınıfı peletler için $\% 3$ 'den düşük olması gerekmektedir. Ancak elde edilen tüm kül içeriği değerleri Avrupa Pelet Konseyi'nce belirlenen standartlara göre yüksek kalmışıtır. Bunun nedeni kimyasal içerik değerlerinin farklı olmasından kaynaklanabilir.

\section{Tablo 5. Peletlerin uçucu madde miktarları, sabit karbon ve kül içeriği değerleri}

Table 5. Volatile matter amounts, fixed carbon and ash content values of pellets

\begin{tabular}{lccc}
\hline Peletler & $\begin{array}{c}\text { Uçucu madde miktarı } \\
\mathbf{( \% )}\end{array}$ & $\begin{array}{c}\text { Sabit karbon } \\
\mathbf{( \% )}\end{array}$ & $\begin{array}{c}\text { Kül içeriği } \\
\mathbf{( \% )}\end{array}$ \\
\hline$\% 100 \mathrm{AK}$ & $52.87 \mathrm{~b}$ & $31.57 \mathrm{a}$ & $7.44 \mathrm{c}$ \\
$\% 100 \mathrm{ZK}$ & $64.83 \mathrm{a}$ & $24.53 \mathrm{c}$ & $10.08 \mathrm{a}$ \\
$\% 75 \mathrm{AK}+\% 25 \mathrm{ZK}$ & $55.51 \mathrm{ab}$ & $31.63 \mathrm{a}$ & $5.97 \mathrm{~d}$ \\
$\% 25 \mathrm{AK}+\% 75 \mathrm{ZK}$ & $63.13 \mathrm{a}$ & $25.62 \mathrm{~b}$ & $9.82 \mathrm{~b}$ \\
$\% 50 \mathrm{AK}+\% 50 \mathrm{ZK}$ & $62.20 \mathrm{a}$ & $21.26 \mathrm{~d}$ & $7.50 \mathrm{c}$ \\
\hline
\end{tabular}

Sattr içerisinde aynı harfleri alan değerler arasında istatiksel olarak anlamlı bir fark yoktur $(P<0.05)$.

\subsection{Peletlere Uygulanan Termogravimetrik Analizler}

TGA; uygun şartlarda isıtılan numunede oluşan kütle değişiminin, zamana veya sıcaklığa bağlı olarak hesaplandığı bir yöntem, DTG ise TGA'nın birinci türevi olup birim zamanda numunede oluşan kütle kaybının belirlendiği bir yöntem olarak tanımlanmaktadır (Şensöğüt, 2002). TGA, yanma özelliklerinin belirlenmesindeki en iyi yöntemlerdendir. Pelet numunelerine ait termogramlarda; kırmızı renkli (azalan) eğri, sıcaklık artışına bağlantılı olarak numune kütlesindeki azalmayı \% cinsinden belirtirken (TGA), mavi renkli (dalgalı) eğri ise sıcaklık artışıyla bağlantılı olarak gerçekleşen kütle kaybını \% cinsinden belirtmektedir (DTG).

Pelet numunelerinin TGA eğrilerinde iki önemli kütle kaybı meydana gelmiştir. İlk kütle kaybı $100{ }^{\circ} \mathrm{C}$ sıcaklıkta gerçekleşmiştir. Maksimum su kütlesi kaybı yaklaşı $\% 8$ ile $\% 100$ AK'da görülmüştür. Bu değer \%75 $\mathrm{ZK}+\% 25 \mathrm{AK}$ 'da yaklaşı $\% 5$ iken diğer numunelerde yaklaşık $\% 7$ olduğu gözlenmiştir. Numunelerin ikinci kütle kayıları $\% 100$ AK'de $132-548{ }^{\circ} \mathrm{C}, \% 100 \mathrm{ZK}$ 'de $176-553{ }^{\circ} \mathrm{C}, \% 75 \mathrm{ZK}+\% 25$ AK'da $170-551{ }^{\circ} \mathrm{C}, \% 75 \mathrm{AK}+\% 25$ $\mathrm{ZK}$ 'de $148-547{ }^{\circ} \mathrm{C}$ ve $\% 50 \mathrm{AK}+\% 50 \mathrm{ZK}$ 'de $161-556{ }^{\circ} \mathrm{C}$ sıcaklıkları aralığında gözlenmiştir. Numunelerin $900^{\circ} \mathrm{C}^{\prime}$ de maksimum kütle kayıp değerleri yaklaşık olarak \%100 AK'da \%89, \%100 ZK'de \%76, \%50 AK+\%50 ZK'de \%80, \%75 ZK+\%25 AK'da \%82 ve \%75 AK+\%25 ZK'de \%88 olduğu belirlenmiştir (Şekil 5-6, Tablo 6).

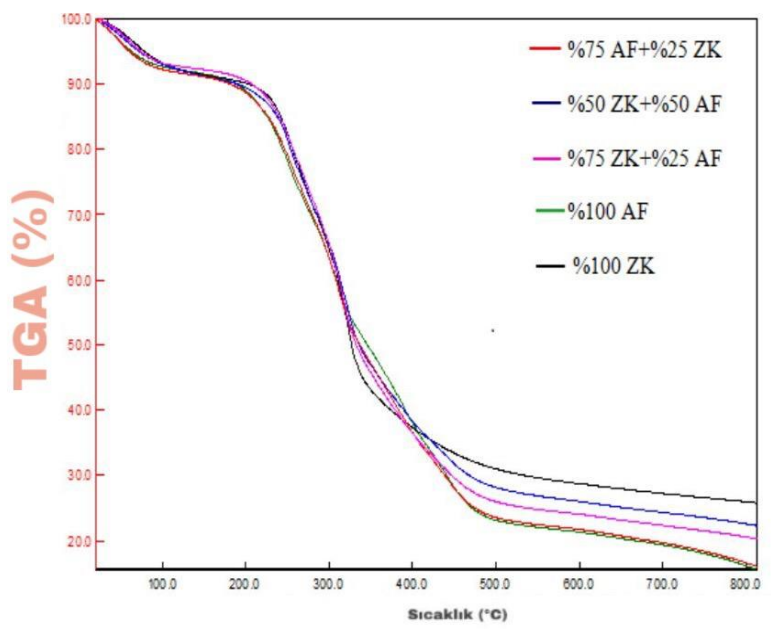

Figure 5. TGA curves of all pellets

\section{Şekil 5. Tüm peletlerin TGA ĕgrileri}

Peletlerin başlangıç bozunma sıcaklıkları; $\% 100 \mathrm{AK}$ 'de $132{ }^{\circ} \mathrm{C}, \% 100 \mathrm{ZK}$ 'de $176{ }^{\circ} \mathrm{C}, \% 75 \mathrm{ZK}+\% 25 \mathrm{AK}$ karışımında $148^{\circ} \mathrm{C}$ ve $\% 75 \mathrm{AK}+\% 25 \mathrm{ZK}$ 'de $170{ }^{\circ} \mathrm{C}, \% 50 \mathrm{AK}+\% 50 \mathrm{ZK}$ 'de $161^{\circ} \mathrm{C}$ olarak belirlenmiştir. ZK oranı artıkça $\mathrm{Ti}\left({ }^{\circ} \mathrm{C}\right)$ değerinde artma meydana gelmiştir Peletlerin maksimum bozunma sıcaklıkları; \%100 AK'de 335 
${ }^{\circ} \mathrm{C}, \% 100 \mathrm{ZK}$ 'de $341{ }^{\circ} \mathrm{C}, \% 75 \mathrm{AK}+\% 25 \mathrm{ZK}$ 'de $327^{\circ} \mathrm{C}$ ve $\% 25 \mathrm{AK}+\% 75 \mathrm{ZK}$ 'de $336{ }^{\circ} \mathrm{C}, \% 50 \mathrm{AK}+\% 50 \mathrm{ZK}$ 'de $324{ }^{\circ} \mathrm{C}$ olarak bulunmuştur (Şekil 5-6, Tablo 6).

Numunelerin final bozunma sicaklikları $\% 100 \mathrm{AK}$ 'da $548{ }^{\circ} \mathrm{C}, \% 100 \mathrm{ZK}$ 'de $553{ }^{\circ} \mathrm{C}, \% 50 \mathrm{AK}+\% 50 \mathrm{ZK}$ 'de 556 ${ }^{\circ} \mathrm{C}, \% 75 \mathrm{ZK}+\% 25 \mathrm{AK}$ 'da $551{ }^{\circ} \mathrm{C}$ ve $\% 75 \mathrm{AK}+\% 25 \mathrm{ZK}$ 'de $547{ }^{\circ} \mathrm{C}$ olarak hesaplanmıştır (Şekil 5-6, Tablo 6). Bozulma sıcaklık değerleri arasındaki farklılıkların bileşenler arasında oluşan reaktivite farklılıklarından kaynaklanmış olduğu söylenebilir. Liu ve ark. (2014), Thek ve Obernberger (2004) final bozunma sıcaklıklarının ve maksimum bozunma sıcaklıklarının yüksek olması pelet yanma ısıl oranını artıracağını ifade etmişlerdir. Bu nedenle peletlerin yakacak olarak kullanılması durumunda ZK oranının artması ile yanma kalitesi yükselecektir.

Numunelerin minimum kütle kayıp oranının \%100 AK'de $3.7 \%$ dak ${ }^{-1}$ olduğu ve maksimum kütle kayıp oranının $\% 100 \mathrm{ZK}$ 'de $7.0 \%$ dak $^{-1}$ olduğu görülmüştür. Bu oran $\% 75 \mathrm{ZK}+\% 25 \mathrm{AK}^{\prime}$ da $5.4 \%$ dak $^{-1}$ iken $\% 50$ $\mathrm{AK}+\% 50 \mathrm{ZK}$ ' de $4.7 \%$ dak $^{-1}$ ve $\% 75 \mathrm{AK}+\% 25 \mathrm{ZK}^{\prime}$ de $4.5 \%$ dak $^{-1}$ olduğu belirlenmiştir (Tablo 6). Karışımlar arası kütle kayıp oranlarında önemli düzeyde farklılık bulunmuştur $(\mathrm{P}<0.05)$.

Uçucu madde miktarlarına bakıldığında (Tablo 5) \%100 ZK’nın yüksek olduğu görülmektedir. Bu durum içerisindeki organik bileşik miktarının fazla olduğunu göstermektedir. Organik madde miktarının fazla olması kütle kaybının artmasını sağlamaktadır. Bundan kaynaklı olarak çalışmada zeytin küspesi oranı arttıkça maksimum kütle kayıp oranını arttığı görülmüştür (Şekil 5-6, Tablo 6).

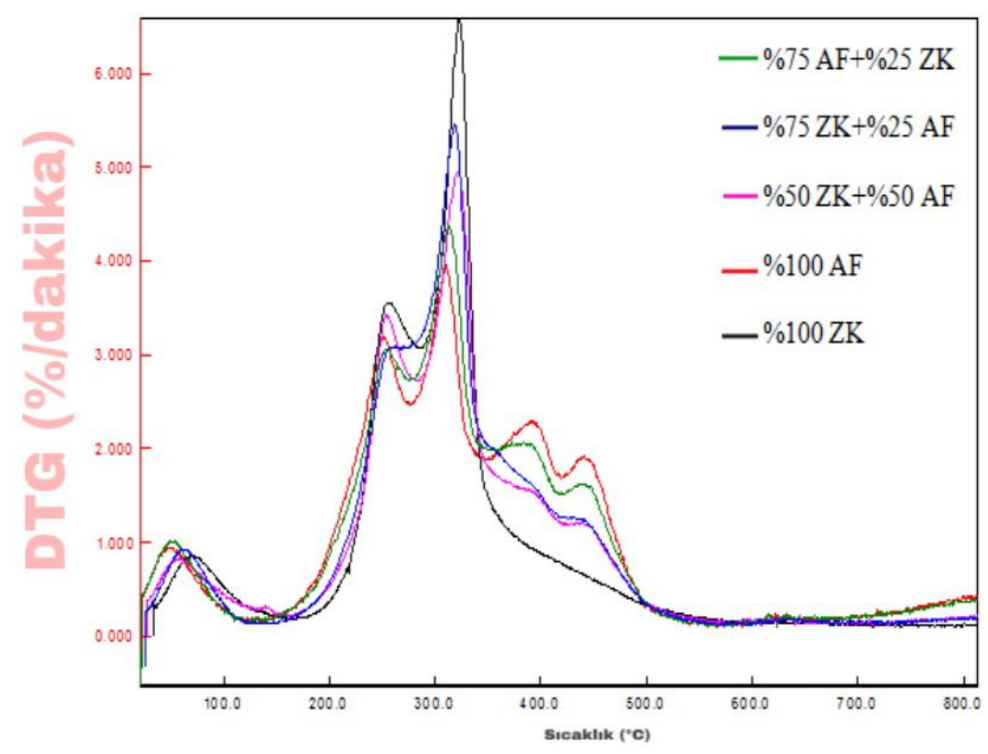

Figure 6. DTG curves of all pellets

Şekil 6. Tüm peletlerin DTG ĕgrileri

Tablo 6. Peletlerin termal bozunma sicaklıklart

Table 6. Thermal decomposition temperatures of pellets

\begin{tabular}{|c|c|c|c|c|}
\hline Peletler & $\begin{array}{c}\mathbf{T}_{\mathbf{i}} \\
\left({ }^{\circ} \mathrm{C}\right)\end{array}$ & $\begin{array}{l}\mathrm{T}_{\max } \\
\left({ }^{\circ} \mathrm{C}\right)\end{array}$ & $\begin{array}{c}\mathrm{T}_{\mathrm{f}} \\
\left({ }^{\circ} \mathrm{C}\right)\end{array}$ & $\begin{array}{c}\text { Kütle kayıp oranı } \\
\left(\% \text { dak }^{-1}\right)\end{array}$ \\
\hline$\% 100 \mathrm{AK}$ & 132 & 335 & 548 & $3.7 \mathrm{~d}$ \\
\hline$\% 100 \mathrm{ZK}$ & 176 & 341 & 553 & $7.0 \mathrm{a}$ \\
\hline$\% 75 \mathrm{AK}+\% 25 \mathrm{ZK}$ & 148 & 327 & 547 & $4.5 c$ \\
\hline$\% 25 \mathrm{AK}+\% 75 \mathrm{ZK}$ & 170 & 336 & 551 & $5.4 b$ \\
\hline$\% 50 \mathrm{AK}+\% 50 \mathrm{ZK}$ & 161 & 324 & 556 & $4.7 \mathrm{c}$ \\
\hline
\end{tabular}

Satır içerisinde aynı harfleri alan değerler arasında istatiksel olarak anlamlı bir fark yoktur $(P<0.05)$. 


\section{Sonuç}

Antep fistığı kabuğu ve zeytin küspesinin, 5 farklı oranda (\%100 AK, \%75 AK+\%25 ZK, \%50 AK+\%50 $\mathrm{ZK}, \% 25 \mathrm{AK}+\% 75 \mathrm{ZK}$ ve \%100 ZK) karıştırılması ile elde edilen peletlerin elemental analizi ve üst ısıl değerleri, pelet parça yoğunluğu, kırılma direnci, dikey sıkıştırma direnci, nem alma direnci, nem içeriği, uçucu madde miktarı, kül içeriği ve termogravimetrik analizler belirlenmiştir.

Yapılan analizlerde elde edilen sonuçlar aşağıdaki şekilde özetlenebilir:

- Peletlerin nem içeriği değerleri Avrupa Pelet Konseyince belirlenen standartlara uygundur.

- ZK oranı artıkça pelet parça yoğunluğunda da artma meydana gelmiştir.

- AK oranı arttıkça dikey sıkıştırma direncinde de artma meydana gelmiştir.

- Peletlerin nem içeriği, EN14774-1 standardında belirtilen değerlerden ( $\leq \% 10)$ küçük olup standartlara uygun olduğu görülmüştür.

- ZK oranı artıkça nem alma oranında artma meydana gelmiştir.

- ZK oranı arttıkça kül içeriğinde artma olmuştur.

- ZK oranı artıkça Ti $\left({ }^{\circ} \mathrm{C}\right)$ değerinde artış görülmüştür.

- Kırılmaya karşı en hassas materyal \%50 AK+\%50 ZK olurken kırılmaya karşı en dayanıklı materyal, \%100 AK olmuştur.

- Pelet çap ve uzunlukları, EN16127 standardına uygun olduğu sonucuna varılmıştır.

- \%100 AK miktarının artması ile pelet dayanımının arttığı belirlenmiştir. Peletler dayanım bakımından değerlendirildiğinde \%100 AK tercih edilmesinin uygun olacağı sonucuna varılmıştır.

- Termogravimetrik ve diferansiyel termogravimetrik analiz sonuçlarına bakıldığında ZK oranı arttıkça maksimum kütle kayıp oranında da artma meydana gelmiştir.

- Peletlerin yakacak olarak kullanılması durumunda ZK oranının artması ile yanma kalitesinde yükselme olacaktır. Yanma açısından en etkin peletler \%100 ZK olan pelet olarak belirlenmiştir.

Konuya ilişkin öneriler:

- Ülkemizde potansiyeli ve çeşitliliği fazla olan fakat değerlendirilmesi düşük olan biyoyakıt kaynakları; pelet şekline getirilip ülke ekonomisine katkı ve çevre kirliliğinin önlenmesinde etki sağlayabilir.

- Enerjide dışa bağımlılığın düşmesi ve potansiyel kaynaklarımızın değerlendirilebilmesi bakımından tarımsal kökenli biyokütle kaynaklarını pelet haline getirerek alternatif enerji üretilebilir.

- Pelet üretimi için kurulabilecek tesisler kırsal alanlarda iş imkanı oluşturabilir.

- Pelet üretimi için yatırımcılar devlet tarafından desteklenip teşvik edilerek yenilenebilir enerji kaynaklarına olan ilgiyi artırabilirler.

\section{Teşekkür}

Bu çalışma Kahramanmaraş Sütçü İmam Üniversitesi, Bilimsel Araştırma Projeleri Koordinasyon Birimi tarafından desteklenmiştir (2018/5-3 YLS). 


\section{Kaynakça}

AOAC. (1990). Official Methods of Analysis. 15th ed. Association of Official Analytical Chemists, Washington, DC. US.

ASTM D3172-13. (2013). Standard Practice for Proximate Analysis of Coal and Coke, ASTM International.

Atay, O., (2015).Yağgülü Damıtma Atıklarının Peletlenmesi Üzerine Bir Araştırma, Yüksek Lisans Tezi, Süleyman Demirel Üniversitesi, Fen Bilimleri Enstitüsü, Tarım Makineleri ve Teknolojileri Mühendisliği, Isparta. 66s.

Atay, O. A., Ekinci, K. (2020). Characterization of Pellets Made From Rose Oil Processing Solid Wastes/Coal Powder/Pine Bark. Renewable Energy, 149, 933-939.

Atay, O.A., Ekinci, K., Üçok, S., Kaçar, H., Kumbul, B.S., Aybek, A. (2018). Şeftali Çekirdeği ve Linyit Kömür Tozundan Yapilan Peletlerin Fiziko Mekanik Özellikleri. Süleyman Demirel Üniversitesi Ziraat Fakültesi Dergisi 1. Uluslararası Tarımsal Yapılar ve Sulama Kongresi Özel Sayıs1, 274-280.

Aybek, A., Üçok, S., İspir, M. A., Bilgili, M. E. (2015). Digital Mapping And Determination of Biogas Energy Potential of Usable Animal Manure and Cereal Straw Wastes in Turkey. Journal of Tekirdag Agricultural Faculty, 12(3), 109-120.

Aydemir, T. (2017). Farklı Tarımsal Artıklar Kullanılarak Hazırlanan Karıșım Peletlerinde Kenevir Sapı Kullanımının Pelet Kalite Özellikleri Üzerine Etkisi. Yüksek Lisans Tezi, Namık Kemal Üniversitesi, Fen Bilimleri Enstitüsü, Tekirdağ, 79.

Başıbüyük, Ü,F. (2020). Pamuk çiğidi küspesi ve kırmızıbiber işleme atıklarından biyoyakıt amaçlı pelet elde edilmesi, Kahramanmaraş Sütçü İmam Üniversitesi / Fen Bilimleri Enstitüsü, Yüksek Lisans Tezi, 49s.

Baileys, R.T, Blankenhorn, P.R. (1982). Calorific And Porosity Development in Carbonized Wood. Wood Sci 1984;15(1):19-28.

Bilgin, S., Koçer, A., Yılmaz, H., Acar, M., Dok, M. (2016). Çay Fabrikası Atıklarınının Peletlenmesi ve Pelet Fiziksel Özelliklerinin Belirlenmesi. Gaziosmanpaşa Üniversitesi Ziraat Fakültesi Dergisi, 1300:2910, 70-80.

Çapik, M. (2012). Present Situation And Potential Role of Renewable Energy in Turkey"; Renewable Energy 46, s.01-13.

Dağtekin M, Gürdil G. A. K. (2021) Pelleting Pruning Residues of Mandarin for Bio-Energy. MKU. Tar. Bil. Derg. 26(1) : 75-81. DOI: $10.37908 /$ mkutbd. 785095

Diken, B., Kayişoğlu, B. (2020). A Research on The Determination of The Gasification Performance of Grass Pellets. Tekirdağ Ziraat Fakültesi Dergisi, 17(1), 24-36.

EN 16127. (2012). Solid Biofuels. Determination of Length And Diameter Of Pellets.

EN 14774-1. (2009). Solid Biofuels. Determination of Moisture Content. Oven Dry Method. Total Moisture. British Standards Institution, London

EN 16127. (2012). Solid Biofuels-Determination of Length and Diameter of Pellets; European Committee for Standardization: Brussels, Belgium.

Fasina, O.O., Sokhansanj, S. (1996). Storage And Handling Characteristics of Alfalfa Pellets. Powder Handling and Processing;8:361-5.

Garcia, R., Pizarro, C., Lavín, A.G., Bueno, J.L. (2014). Spanish Biofuels Heating Value Estimation Part II: Proximate Analysis Data. Fuel, $117,1139-1147$.

ISO 562. (2010). International Standarts, Hard Coal And Coke, Determination of Volatile Matter.

Kaliyan, N., Morey, R.V. (2009). Factor Affecting Strength And Durability Of Densified Biomass Products. Biomass and Bioenergy, 33: 337359.

Karaosmanoğlu, F. (2006). Biyoyakıt Teknolojisi ve İTÜ Araştırmaları. ENKÜS 2006- İTÜ Enerji Çalıştayı ve Sergisi. s: 110-125. 22-23 Haziran, İstanbul, Türkiye.

Liu, Z., Quek, A., Balasubramanian, R. (2014). Preparation And Characterization of Fuel Pellets From Woody Biomass,Agro-Residues And Their Corresponding Hydrochars. Applied Energy, 113: 1315-1322.

Öztürk, H.H. (2012). Enerji Bitkileri ve Biyoyakıt Üretimi, Hasad Yayıncılık Ltd. Şti., İstanbul, 272 s.

Özdemir, S., Er, A. (2018). Tavuk Gübresi ve Tarımsal Atıkların Biyoyakıt Karakterlerinin İncelenmesi. Sakarya Üniversitesi Fen Bilimleri Enstitüsü Dergisi, 22(2), 489-494.

Şenpınar A., Gençoğlu M.T., (2006). Yenilenebilir Enerji Kaynaklarının Çevresel Etkileri Açısından Karşılaştırılması॥ Doğu Anadolu Bölgesi Araştırmaları

Şensöğüt, C., Yıldırım, Ö. S., Çınar, İ., Özdeniz, A. H. (2002). Bazi Yerli Kömürlerin Termogravimetrik Karakteristiklerine İstatistiksel Yaklaşim”, Türkiye 13 Komur Kontesi Bildiriler Kitab1, 29-31 Mayıs 2002, Zonguldak, Türkiye, s. 145-150.

Tabil, L.G., Sokhansanj, S. (1996). Pocess Conditions Affecting The Physical Quality of Alfalfa Pellets. Applied Engineering in Agriculture, 12: $345-350$ 
JOTAF/ Journal of Tekirdag Agricultural Faculty, 2021, 18(4)

Thek, G. Obernberger, I. (2004) Wood Pellet Production Costs under Austrian and in Comparison to Swedish Framework Conditions. Biomass and Bioenergy, 27, 671-693.

Tırıs, Ç. (2014). Biyokütle Enerji İçerikleri ve Biyokütle Karakterizasyonu Ege Üniversitesi Güneş Enerjisi Enstitüsü 2014 Kış Okulu

TS ISO-1171. (2014). Tüm Katı Mineral Yakıtların Kül Miktarının Tayini Yöntemi, Türk Standartları Enstitüsü, Ankara.

TS 711 ISO-562. (2002). Uçucu Maddenin Tayin Methodu, Türk Standartları Enstitüsü, Ankara.

Yılmaz, H. (2014). Bazı Tarımsal Artıkların Peletlenmesi ve Pelet Fiziksel Özelliklerinin Belirlenmesi Üzerine Bir Araştırma. Yüksek Lisans Tezi, Akdeniz Üniversitesi, Fen Bilimleri Enstitüsü, Tarım Makinaları ve Teknolojileri Mühendisliği A.B.D. 